\title{
Reform and Practice of Strengthening Application- Oriented IT Internship \& Training and Promoting Information Management Specialty Level
}

\author{
Kang-lin Gao \\ Management Science and Engineering School \\ Shandong University of Finance and Economics \\ Jinan City, China \\ gkl_sd@126.com
}

\author{
Mei Dong \\ Information Science and Engineering School \\ Jinan University \\ Jinan City, China \\ mei_dong_2004@126.com
}

\begin{abstract}
It is very important to promote information quality of college students for their creatively acquiring, processing and applying effective information at the age of Big Data. In line with the requirements of present social development for applicationoriented information technology undergraduates the paper has done some useful studies and achieved good results in building up a new practical curriculum, improving teaching methods and means with an aim to train students to lay down theoretical basis and applying abilities.
\end{abstract}

Keywords_Practical curriculum;Teaching methods;Practical teaching reform;Cultivae talents.

\section{INTRODUCTION}

Along with the successive deepening of social informatization, more knowledgeable and networking the information society has presented a series of requirements for talents including their information attainment. The cultivation of information attainment concerns livelihood and development of each member of society and so every country pays high attention to it. In 2012 and along with coming of the age of Big Data a higher requirement for the information attainment has been put forward.

Selecting, obtaining and processing of information directly affect the knowledge updating and scientific result transformation. College students are "reserves" for our country's future builders so it is very significant for them to effectively obtain, process and apply information through promoting their information attainment.

The correlated curriculum of information management and system is of stronger comprehensiveness and wider range, concerning multi-field knowledge such as computer science, software development, business administration, data processing, control theory and signal processing etc. All these various subjects are mutually crossed, integrated and infiltrated, and some courses are both of stronger theory and practice. Thus it presents a higher requirement for teaching and learning. So it will be our research emphasis to well integrate theory with practice so as to reinforce their theoretical knowledge, and at the same time promote their engineering and practical abilities.

The existing problem at present is that quite a few students lack awareness of the subject's importance and don't know how to orientate their study, thus affecting their study interests and failing to clearly target their employment. Based on many years of teaching practice we have undergone practical teaching reform of some related curriculum and achieved good results.

\section{EXPLORING NeW TEACHING MOdELS AND CONSTRUCTING GOOD EDUCATION ENVIRONMENT}

\section{A. Guiding Idea}

With the experimental teaching system and curriculum content innovation as its core, and with promoting students' practical ability and cultivating their innovative spirits as its goal we are constantly improving IT experimental teaching system and innovating personnel training models and teaching management mechanism. Training students has transformed from knowledge type to quality one, from imitation to innovation and from being unitary to compound, thus enhancing their comprehensive abilities. So they will become high-quality IT talents with stronger innovative spirits and practical capabilities.

\section{B. Structuring New Experimental Practical Curriculum System}

From the angle of cultivating innovative talents we have optimized and reorganized the existing experimental curriculum. By rebalancing the proportion of the three aspects of knowledge instruction, ability training and quality promotion we have built a new integrated multi-layered open experimental curriculum system and implemented it in classifications. We have a unified planning, 
management and arrangement of the experimental curriculum. The experiment content should reflect the principles of emphasizing basic theory and skills, curriculum comprehensiveness and instruction according to students' aptitudes. It should also reflect the three-layer experiment types of basic training, integrated designing and researching. By offering a certain number of appointed and optional experimental projects and combining with teachers' R\&D tasks we instruct students to accomplish their research-type optional experimental subjects. Meanwhile we also closely integrate in-class experiment with after-class practice and take it as an important part of students' experimental practice activities. We have also made full use of the computer-hobby and projectdevelopment teams to encourage students to participate in enterprises and teachers' projects and achieved good results.

\section{Improving Experimental Teaching Methods and Means}

We have entirely infiltrated scientific research and application into undergraduate experimental teaching with a focus of cultivating students' innovative spirits, practical ability, cooperation competence and sustainable development capacity. We have revised practical parts in the new teaching program and made out an overall teaching plan. On this basis we have begun to build up experimental projects and cases store so as to form an accumulated experimental case-store management mechanism. Moreover we have also built online teaching classrooms to benefit both teachers and students so as to reach the purpose of reinforcing knowledge and enhancing ability. In future we will try to build campus network virtual experiment environment, accumulate experience and strengthen IT practice research. Aiming at the requirements for students in the areas of software development technology, computer equipment and system development we will undergo some new research in MIS system development, basic experimental application framework etc, in order to supply students' experimental results with a learnable bracing framework and highlight their compulsory core experimental tasks. We will also establish a training mechanism for talented students and offer them more experimental space.

\section{MAIN COURSE PRACTICE}

\section{A. 《(Advanced Language Program Design》}

The course of 《Advanced Language Program Design》 is foundation course for IT undergraduate program. The C language is its basis and through studying basic programming concepts and methods students can master the basic knowledge and concepts of advanced language program design and the programming ideas and techniques, learn to use $\mathrm{C}$ language in programming and enhance abilities of analyzing \& solving problems so as to lay down a solid foundation for further study of program development and engineering computing software development. As is stronger in theory and practice the course should highlight the basic principles of linking theory with practice, emphasize computer experiment, require a good master of $\mathrm{C}$ language in developing commonly used programs and know very well the basic approach of software designing and basic process of program debugging. We have chosen Tan Haoqiang' s 《Program Design in C》 as textbook and arrange 9 experimental classes in practical section, once in every two weeks and totaling 18 periods. Its development environment is $\mathrm{VC}++$ and the experiment is organized in the following three parts. The first is to establish the basic framework of $\mathrm{C}$ program (main ()\{\} ,vividly called gate or yard framework) so as to enable students to grasp the basic methods of programming and debugging. The second is to emphasize the three basic structures (sequence, option and cycling) and its function part. The third is to constantly expand the range of knowledge and guide students to extend from simple variable to array, pointer and structure variables. The experiment includes not only verification topics but also design subjects and a few selective innovative ones.

\section{B. 〈'Management Information System》}

《Management Information System》 adopts multi-teaching methods in teaching activities. The teaching forms include classroom instruction, group report, scenario analysis, case discussion, after-school group assignment and analog system development etc. Huang Tiyuan and Li Yijun's 《Management Information System》 (The Fifth Edition) is chosen as textbook. In teaching organization we try to handle correctly the relationship between classical development theories and new technologies with an emphasis on system analysis, system design and system implementation as the principal line and require students to grasp basic analytical and designing methods in order to lay a good foundation for future system development and graduation project. With instruction one experiment is arranged every two weeks and so there are 9 experiments totaling 18 periods in all. The previous three experiments involve website design and web database experiment. Students are required to finish two tasks. One is to understand server and client's system operation through writing ASP library inquire system (use Access database). It mainly involves form designing, ASP program parameter passing, SQL statement reading database list and Web page display etc. The other is to run a rather complete e-commerce website, establish a whole MIS concept and foreground-background framework concept. The later 6 experiments are arranged for system analysis, system design and system implementation with classroom instructions. In line with teaching requirements students are grouped (with 6 in one) to do outside-class analog system word including system analysis, system design and system implementation. In the end each group report and display their work and hand in their assignments (as main assignments). Their practical examination result evaluation is comprehensively determined according to their project performance and contribution. 


\section{C. 《Enterprise Resource Planning》}

Enterprise resource planning provides enterprise information-based construction with an overall integrated solution. We select Luo Hong' s 《ERP: Principle, Design and Implementation》 as textbook. It is divided into several parts such as cases, principles, design and implementation. The main line of the course involves ERP's formation and development, its basic concept, master production schedule, MRP, CRP, workshop management, stock control, purchase, finance, fixed assets, cost management, human resource etc. Each chapter begins from a specific case and then the question is followed up with related knowledge instruction and discussion. For instance, in teaching master production schedule we use some specific example of an enterprise in deciding what, how many and when it produces to introduce the master production schedule concept. In teaching calculation of the master production schedule instruction should be of explicitness and succinctness, memorable instead of abstract. For instance, in calculation just introduce on the basis of known data such as predicted and order quantity to determine gross demand. Then we can use related formula to determine net demand in each phase, estimate available inventory, work out planned output and planned investment, predict available sales volume and finally accomplish the whole master manufacturing plan sheet calculation (also material requirements planning calculation). 9 experiments are arranged totaling 18 periods. We adopt 《Integrated Production, Purchase, Sales and Finance Management System Software》 with 《Okra ERP Software 》 because the two soft-wares are easy for installation dispense with installing database but complete with computer guidance video. The previous five experiments use ERP software mainly including basic data preparation (operator management, supplier management, goods management, working procedure management, worker management etc.), order management (MRP operation for customer order, order analysis etc.), purchasing management (inner purchase examination, purchase plan, purchase order, AOG schedule management), production management (production order handling, picking analysis, procedure analysis etc.). The later 4 experiments mainly use Okra ERP software and require students to know the composition of ERP system modules and transfer mode of subsystems in ERP's internal system, and use ERP system to finish production management independently. The system is composed of basic setup, personnel management, finance management, purchase-sales-inventory management, production system, distribution system, Internet system modules etc. with a focus on modules of finance, personnel and production.

\section{D. 《Management Information System Practical Training》}

《Management Information System Practical Training》 is an extended course of management information system focusing on students' MIS development ability. We strengthen cultivating students' development ability on the basis of their grasp of Java and database principle. There are two key links here. One is practical training of ASP+access development by referring to and adopting development case and program in 《Management Information System Principle and Development》 (by Ma Xiulin). The other is practical training of JSP+MySQL development by consulting and using program case in 《Java Web Development and Practice $\rangle$ (by Gao Xiang and Li Zhihao). Computer practical training totals 36 periods among which the first part of ASP development consists of 8 periods focusing on students' commanding backend database setup, main frame realization and all module function realization methods through analyzing and studying case procedure. The second part is made up of 28 periods. 1.4 periods are for software development environment setup requiring students to install JDK, Tomcat, MySQL, Eclipse, etc. independently. 2. 6 periods are for Mysql database requiring students to grasp MySQL installation \& configuration, basic operations of database, data sheet, data query, data insertion, update \& deletion, data import \& export. 3. 18 periods are for JSP development mainly including Java Web development environment, basic grammar, JSP built-in object, JavaBean, servlet, database development and more advanced Struts 2 framework, Hibernate, Spring technology etc. The basic case in JSP practical training is a living example of shopping cart. Students must grasp its programming which can realize the operation of database's addition, deletion, revision, checking and listing. In addition it also offers optional course design cases. One is a comprehensive eshop and the other is Servlet-based library management system. Through case study students can master systematic development flow and lay down a better foundation for software designing. The practical training also requires students to finish appointed project design and hand in software and related documents in the end.

\section{E. 《Undergraduate Employment \& Entrepreneurship Guidance》}

In line with undergraduate employment and entrepreneurship education requirements we bring such an education into compulsory course arrangement. Through introducing employment situation \& tendency as well as instruction \& practice 《Undergraduate Employment \& Entrepreneurship Guidance》 helps students learn some basic knowledge of employment and its guidance, tries to meet personalized demands and implement innovative \& business training. Its main chapters include situation \& policy, career planning, profession, employment \& occupation, self-cognition, career choice, preparation for employment, resume, interview \& written examination preparation etc. In its teaching method we have undergone a reform. For instance we combine instruction with group discussion, strengthen interaction between teaching and learning and intensify interview scene training such as structured interview, leaderless group discussion etc. to benefit every student. In business start-up training we focus on case study and offer lectures by outside experts and successful graduates. In addition we have also done some probe in models of learning such as PBL (problem-base learning) and SCL (student-centered learning). 


\section{OTHER EXPERIENCE}

\section{A. Promoting student quality is a systematic engineering}

Through teaching practice we realize that student quality cultivation is a systematic engineering and needs all-level leaders, teachers, instructors and all departments of schools join efforts to work. So we must strengthen construction of a professional teaching force, specialties, teaching attitude, learning styles and examination moods. This needs all-level managerial staff, teachers and students jointly build a good education environment and learning atmosphere. Only by this are our graduates able to stand all tests, thus increasing the employment rate. Meanwhile we also need to establish a good relationship with off-campus employers and make customized training program in line with social demands. In this way we can meet the requirements of Ministry of Education for undergraduate program on one hand and requirements of different employers for students' application and innovation capabilities. In order to integrate well with markets and solve the problem of lacking full combination between teaching and practicing we need to integrate teaching link into enterprises' real needs so as to lay down a good foundation for graduates to quickly adapt to enterprise work.

\section{B. Encourage and organize students to participate in all kinds of scientific \& technological innovation and contest activities}

We pay attention to Two Combinations in the experiment and practice teaching. That is the close combination between experiment teaching and enterprise practical application, and that between experiment teaching and innovation \& entrepreneurship in order to offer support to students in their entrepreneurship \& scientific research and provide powerful guarantee in their science \&technology innovation activities. In order to open up students' view we also encourage and guide them to participate in all kinds of science \& technology contests and innovation activities, equip them with specialized advisers in their competitions and selections and give them financial support as well. In these respects we have achieved good results.

\section{CONCLUSION}

IT courses concerning information management and system majors are of strong theory and practice and so they play a very important role in practical teaching. So far there are arising a lot of research contents, hot-spot research direction and new results. Arming to these features we have summed up our teaching experience and partial IT course teaching \& reforming practice and made a rather deep study and probe in reforming practical teaching, designing experiment teaching links, improving evaluation modes and have achieved some good achievements in teaching and practice. In future we will further sum up experience and make deeper reform in classroom teaching and practical training in order to cultivate and enhance students' innovative awareness and thinking, increase their operational abilities and innovation capacities so as to lay down a solid foundation for their future in-depth research and development work.

\section{REFERENCES}

[1] Liu Xiaowei, Yin Zimin and Zhang Caihong, “A Probe in Structuring Information and Information System Specialty Practical Teaching System,” [J], Liaoning Polytechnic University Journal, August, 2014 (4th Issue, volume 16)

[2] Gao Yan, "Construction of Information Management Specialty Curriculum Group at Age of Big Data,”[J], Computer Education, 12, 2014(24)

[3] Peng Zucheng, Li Hui, "A Probe in Information Management Specialty Feature Courses Based Upon ERP Talent Demands, Machinery Design and Manufacture Engineering,", 10th Issue, 2015.

[4] Jia Ping, “A Probe in Information Management Specialty Core Course Group Teaching Reform,” [J], Higher Science Education, 1 st Issue, 2014.

[5] Zhao Jiaojie, Huang Shuwei, "An Analysis in Higher Learning Institute Information Management Specialty Practical Teaching Reform Based Upon Innovation Ability Training,’[J], Liaoning Education Administration College Journal, 4th Issue, 2015. 